\title{
Dietary fried fish intake increases risk of CVD: the REasons for Geographic And Racial Differences in Stroke (REGARDS) study
}

\author{
Fadi Nahab ${ }^{1, *}$, Keith Pearson ${ }^{2}$, Michael R Frankel ${ }^{1}$, Jamy Ard ${ }^{3}$, Monika M Safford ${ }^{4}$,
} Dawn Kleindorfer ${ }^{5}$, Virginia J Howard ${ }^{6}$ and Suzanne Judd ${ }^{7}$

'Department of Neurology, Emory University, 1365 Clifton Road NE, Clinic B, Suite 2200, Atlanta, GA 30322, USA:

${ }^{2}$ Department of Nutrition Sciences, School of Health Professions, University of Alabama at Birmingham, Birmingham, AL, USA: ${ }^{3}$ Department of Epidemiology and Prevention, Wake Forest University Baptist Medical Center, Winston-Salem, NC, USA: ${ }^{4}$ Department of Medicine, University of Alabama at Birmingham, Birmingham, AL, USA: ${ }^{5}$ Department of Neurology, University of Cincinnati, Cincinnati, OH, USA: 'Department of Epidemiology, School of Public Health, University of Alabama at Birmingham, Birmingham, AL, USA: 'Department of Biostatistics, School of Public Health, University of Alabama at Birmingham, Birmingham, AL, USA

Submitted 30 December 2015: Final revision received 3 May 2016: Accepted 9 May 2016: First published online 24 June 2016

\begin{abstract}
Objective: The objective of the present study was to examine the relationship of dietary fried fish consumption and risk of cardiovascular events and all-cause mortality.

Design: Prospective cohort study among participants of the REasons for Geographic And Racial Differences in Stroke (REGARDS) study who resided in the USA.

Setting: The primary outcome measures included the hazard ratios (HR) of incident CVD including first incident fatal or non-fatal ischaemic stroke or myocardial infarction and all-cause mortality, based on cumulative average fish consumption ascertained at baseline.

Subjects: Participants ( $n$ 16 479) were enrolled between 2003 and 2007, completed the self-administered Block98 FFQ and were free of CVD at baseline.

Results: There were 700 cardiovascular events over a mean follow-up of $5 \cdot 1$ years. After adjustment for sociodemographic variables, health behaviours and other CVD risk factors, participants eating $\geq 2$ servings fried fish/week $(v .<1$ serving/ month) were at a significantly increased risk of cardiovascular events ( $\mathrm{HR}=1.63$; $95 \%$ CI 1.11, 2.40). Intake of non-fried fish was not associated with risk of incident CVD. There was no association found with dietary fried or non-fried fish intake and cardiovascular or all-cause mortality.

Conclusions: Fried fish intake of two or more servings per week is associated with an increased risk of cardiovascular events. Given the increased intake of fried fish in the stroke belt and among African Americans, these data suggest that dietary fried fish intake may contribute to geographic and racial disparities in CVD.
\end{abstract}

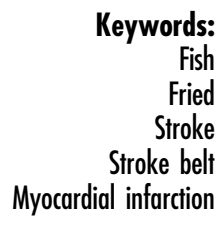

For more than 70 years, excess stroke mortality rates have existed in the Southeastern USA giving rise to the label 'stroke belt' for this region ${ }^{(1-3)}$. Overall stroke mortality rates have been estimated to be about $20 \%$ higher in the stroke belt compared with the rest of the country and various factors have been proposed to explain this geographic disparity in stroke, including increased stroke case fatality rates, prevalence of traditional stroke risk factors, socio-economic status, quality of health care and dietary factors ${ }^{(3,4)}$. Recent data have suggested that the increased stroke mortality in this region can be partially attributed to an increased incidence of stroke although a significant part of this excess risk remains unexplained ${ }^{(5)}$.
Racial disparities in stroke incidence have also been recognized as the likely cause of increased stroke mortality rates among African Americans compared with white Americans aged $\geq 45$ years $^{(5-8)}$.

While regional and racial differences in diet have been proposed as potential contributors to the disparities in stroke, there have been limited data evaluating dietary habits and their potential contribution to excess CVD incidence in the stroke belt and among African Americans. Fish represents the main dietary source of the long-chain $n-3$ fatty acids EPA and DHA. These $n$ - 3 fatty acids have been shown to have favourable effects on platelet aggregation, blood pressure, lipid profile, endothelial 
function and ischaemic stroke risk ${ }^{(9-26)}$. Supplementation with $n$-3 fatty acids has been evaluated in randomized, double-blind, placebo-controlled trials in CVD, with some studies showing a reduction in myocardial infarction (MI) among patients with known CVD, sudden death after MI and mortality in congestive heart failure patients ${ }^{(27-31)}$, while other studies have shown no benefit ${ }^{(32-35)}$. The American Heart Association currently recommends consumption of at least two fish meals per week with an emphasis on oily fish species high in $n$-3 fatty acids for persons without documented CVD and to consider additional supplements of EPA and DHA for those with documented CVD ${ }^{(36)}$.

We previously reported that persons who were living in the stroke belt were less likely to consume at least two weekly servings of non-fried fish but more likely to consume at least two weekly servings of fried fish than those living in the non-belt region ${ }^{(37)}$. We also found that African Americans were more likely than whites to consume two or more weekly servings of fried fish. These differences remained evident even after adjusting for potential confounders including such as age, sex, socioeconomic status and total energy intake. The objective of the present study was to examine how fish consumption and the mode of cooking of the fish are associated with incident CVD, cardiovascular mortality and all-cause mortality in African Americans and whites living inside and outside the stroke belt.

\section{Participants and methods}

\section{Study population}

The REasons for Geographic and Racial Differences in Stroke (REGARDS) study is a national longitudinal cohort study with oversampling of African Americans and persons living in the stroke belt region of the USA, an area that has stroke mortality rates higher than the rest of the country $^{(4)}$. Between January 2003 and October 2007, 30239 individuals were enrolled, including 58\% whites and $42 \%$ African Americans, 55\% women and $45 \%$ men. The sample included $21 \%$ of participants from the 'stroke belt buckle' (coastal plain region of North Carolina, South Carolina and Georgia), 35\% from the stroke belt states (remainder of North Carolina, South Carolina and Georgia, plus Alabama, Mississippi, Tennessee, Arkansas and Louisiana) and the remaining $44 \%$ from the other forty contiguous states (referred to as 'non-belt').

Individuals were identified from commercially available lists of residents and recruited using an initial mailing followed by telephone contact. Using a computer-assisted telephone interview, trained interviewers obtained demographic information, medical history and an array of other potential risk factors. A brief physical examination including blood pressure measurements, blood samples and an electrocardiogram (ECG) was conducted in-person, 3-4 weeks after the telephone interview. Self-administered questionnaires including the Block98 FFQ (NutritionQuest ${ }^{\mathrm{TM}}$, Berkeley, CA, USA) were left with the participant to gather additional information. The telephone response rate was $33 \%$ and the cooperation rate was $49 \%$, similar to other epidemiological studies. Additional methodological details are provided elsewhere ${ }^{(4,5)}$.

\section{Dietary assessment}

The FFQ assessed usual dietary intake over the past year. The five questions specific to fish intake were the following: (i) 'How often do you eat oysters?' (ii) 'How often do you eat other shellfish like shrimp, scallops or crabs?' (iii) 'How often do you eat tuna, tuna salad or tuna casserole?' (iv) 'How often do you eat fried fish or a fish sandwich, at home or in a restaurant?' (v) 'How often do you eat other fish, not fried?' Participants selected from the following options for each question: 'never', 'a few times per year', 'once per month', '2-3 times per month', 'once per week', 'twice per week', '3-4 times per week', '5-6 times per week' and 'every day'. The study had an active tracking process to contact participants to return languishing questionnaires. For the current analysis we excluded the top and bottom $1 \%$ of total energy intake (kcal/d) and individuals who did not answer $85 \%$ or more of the questions on the FFQ ( $n$ 8547), leaving $72 \%$ of the original cohort with usable dietary data.

Fish intake was categorized as $<1$ serving/month, 1-3 servings/month, 1-1.99 servings/week and $\geq 2$ servings/ week to evaluate the current American Heart Association guideline recommendations of at least two weekly servings of fish with a high concentration of $n-3$ fatty acids $^{(28)}$. Fried fish consumption was the sum of all fried fish and fish sandwich. Non-fried fish consumption was the sum of all fish intake excluding the fried fish or fish sandwich.

\section{Outcome assessment}

The primary outcome of the present study was a composite cardiovascular outcome including first incident of fatal or non-fatal ischaemic stroke or MI. Secondary outcomes included all-cause and CVD mortality. All outcomes occurring through 31 December 2010 were available for the analysis.

Participants or their proxies were contacted every 6 months by telephone to identify hospitalizations, emergency department visits, overnight stays in nursing homes or rehabilitation centres, or death during the previous 6 months. For proxy-reported deaths, interviews were conducted with the next of kin. Procedures for adjudication of ischaemic stroke events have been reported previously $^{(5)}$. Briefly, a nurse performed an initial review to exclude obvious non-cases. Medical records were then reviewed by at least two physician members of a committee of stroke experts to validate and classify potential 
ischaemic strokes. Disagreements were resolved by full committee review.

Ischaemic stroke events were defined following the WHO as 'rapidly developing clinical signs of focal, at times global, disturbance of cerebral function, lasting more than 24 hours or leading to death with no apparent cause other than that of vascular origin'(38) and were classified as ischaemic or haemorrhagic. Events not meeting this definition, but characterized by symptoms lasting $<24 \mathrm{~h}$ with neuroimaging consistent with acute ischaemia or haemorrhage, were considered clinical strokes and also counted as events in the present analysis. Only ischaemic strokes were included in the composite CVD outcome in the analysis.

Procedures for adjudication of MI events have also been reported previously ${ }^{(39)}$. Briefly, the MI events were expertadjudicated, examining medical records for clinical signs or symptoms consistent with ischaemia, enzymatic signs of ischaemia characterized by a rising and/or falling pattern of troponin (or, if unavailable, creatine phosphokinase MB fraction) with a peak at least twice the upper limit of normal, or ECG results suggesting ischaemia/MI. Events were adjudicated independently, with a $\kappa$ statistic for agreement between adjudicators of $>0 \cdot 8$. Definite MI events possessed diagnostic enzymes or ECG. Probable MI events were those in which the participant possessed elevated but not diagnostic enzyme levels with a positive but not diagnostic ECG. A positive but not diagnostic ECG in conjunction with ischaemic signs and symptoms was also considered a probable MI in absence of enzymatic data. Definite or probable MI events were counted in these analyses.

Mortality data including confirmation of death, date of death and cause of death were collected through the participants' next of kin, reviewing medical records and death certificates, and from searching online databases such as the National Death Index and the Social Security Death Index. All-cause mortality was defined as any participant who died after the date of enrolment. CVD mortality was defined as death determined to be caused by definite, probable or possible MI; sudden death; heart failure; stroke; ruptured aortic aneurysm; pulmonary embolism; or other heart-related condition ${ }^{(40)}$.

\section{Covariate assessment}

Age, race, sex, region, income and education were obtained by self-report. Height, weight and blood pressure measurements were collected during the in-home visit by a trained medical professional. BMI was calculated from the height and weight measurements. Information regarding physical activity, smoking status, aspirin use and current hypertensive medication use was obtained from self-report. Participants were considered to have diabetes if their fasting blood glucose was $\geq 126 \mathrm{mg} / \mathrm{dl}$, non-fasting blood glucose was $\geq 200 \mathrm{mg} / \mathrm{dl}$, or if they were currently taking any medications or insulin to manage diabetes. Participants were classified as having dyslipidaemia if their total cholesterol was $\geq 240 \mathrm{mg} / \mathrm{dl}$, or LDL cholesterol was $\geq 160 \mathrm{mg} / \mathrm{dl}$, or HDL cholesterol was $\leq 40 \mathrm{mg} / \mathrm{dl}$, or were currently using lipid-lowering medication. Total energy intake and Mediterranean diet score were calculated from the analysis of the Block98 FFQ. Detailed information on the construction of the Mediterranean diet score in the REGARDS cohort has been published previously ${ }^{(41)}$.

For the current analysis we excluded fifty-six individuals due to anomalous data. Of the remaining 30183, we excluded all participants with unusable or missing dietary data ( $n$ 8547), participants with a prior history of stroke or transient ischaemic attack at baseline ( $n$ 1933), participants with a history of CVD (self-reported MI, coronary artery bypass graft, angioplasty, stenting or evidence of MI from ECG; $n$ 3037), participants with no follow-up or errors in follow-up time ( $n$ 186) and participants who had an incident stroke following the telephone interview but before the in-home examination ( $n$ 1). These exclusions provided the primary analysis cohort with 16479 participants of the 30239 enrolled. Comparison of study participants with those excluded due to unusable or missing dietary data revealed that those excluded were more likely to be male, African American, older than 75 years, obese, to live outside the stroke belt and buckle, have an annual income of less than \$US 20000 and to have less than a high-school education compared with our primary analysis cohort ${ }^{(37)}$.

\section{Statistical analyses}

All statistical analyses were assessed at a level of significance of $0 \cdot 05$. The $\chi^{2}$ test and ANOVA were used to compare proportions and evaluate mean differences in descriptive characteristics. Time to event was calculated as the number of days between the participants' in-home examination and the cardiovascular event. Haemorrhagic strokes were not considered events in the present analysis and were censored at the date of the haemorrhagic stroke. Participants who did not have a cardiovascular event were censored at the date of last follow-up, date of death or 31 December 2010, whichever occurred first.

Cox proportional hazards analysis was used to estimate the hazard ratios (HR) for incident CVD, all-cause mortality and CVD mortality, by intake of fried and non-fried fish, in a series of models adjusting for differences in sociodemographic characteristics (age, race, sex, region, income and education), health behaviours (physical activity, smoking status, Mediterranean diet score, aspirin use and total energy intake) and other CVD risk factors (hypertensive medication use, diabetes status, systolic blood pressure, BMI and dyslipidaemia). Participants with non-missing values for all covariates were included in each model, resulting in $0 \%, 0 \cdot 0003 \%, 3 \cdot 4 \%$ and $12 \cdot 1 \%$ of missing data for each model, respectively. 
Additionally, an interaction term was included in the fully adjusted models to explore any potential effect modification of race, income or education with fried and non-fried fish consumption and CVD risk. Although the influence of confounding by diet quality was examined by including the Mediterranean diet score in model 2, a sensitivity analysis additionally examined the confounding effects that consumption of other fried foods (French fries, fried potatoes, fried chicken, bacon) and intake of meat, fruit, vegetables and grains may have on the relationship between fish intake and CVD incidence. Lastly, another sensitivity analysis was conducted including 4926 participants with a history of stroke, transient ischaemic attack or CVD to evaluate the impact that excluding these participants may have on the association between fish intake and CVD. All analyses were conducted using the statistical software package SAS version 9.4.

\section{Results}

A total of 700 participants had an incident CVD event during a mean follow-up time of $5 \cdot 1$ years. The baseline characteristics of the study population by frequency and type of fish consumption are shown in Table 1. Of the study participants, 34\% were African Americans, 59\% were female, $56 \%$ lived in the stroke belt or buckle, and $74 \%$ were overweight or obese (BMI $\geq 25.0 \mathrm{~kg} / \mathrm{m}^{2}$ ).

The HR of incident CVD according to fried and non-fried fish consumption are shown in Table 2. In a crude model, fried fish consumption of $\geq 2$ servings/week was associated with a significant increase in risk of incident CVD events compared with those consuming $<1$ serving fried fish/ month (HR $=1 \cdot 67 ; 95 \%$ CI 1.17, 2.39; $P$ for linear trend $<0.0001)$. Addition of socio-economic covariates somewhat attenuated the point estimates of this relationship but the association remained significant (HR $=1.47 ; 95 \%$ CI 1.02 , 2.12; $P$ for linear trend $=0 \cdot 02$ ). Further adjustment for health behaviours and cardiovascular co-morbidities strengthened the association (model 3: HR $=1 \cdot 63 ; 95 \% \mathrm{CI} 1 \cdot 11,2 \cdot 40 ; P$ for linear trend 0.03). Additionally, in a crude model, non-fried fish consumption of $\geq 2$ servings/week was associated with a significant decrease in risk of CVD compared with those consuming $<1$ serving non-fried fish/month $(\mathrm{HR}=0.73$; $95 \%$ CI $0.54,0.98 ; P$ for linear trend $=0.02$ ). However, addition of covariates to the model attenuated the point estimates and the linear relationship no longer remained significant (Table 2).

In analyses examining the potential effect modification of race, income and education, no significant interactions were found between any of these variables and fried and non-fried fish intake with CVD risk. However, after performing a post hoc analysis examining the stepwise addition of covariates in relation to changes in point estimates, the point estimate attenuation between crude models and sociodemographic-adjusted models (model 1) observed in participants consuming $\geq 2$ servings fried fish/week can be mostly attributed to adjustments made for income and education. Subsequently, the increase in the point estimate observed for this same group after adjustment for health behaviours (model 2) can largely be attributed to adjustments made for exercise frequency.

Sensitivity analyses including adjustment for other fried food intake, meat, fruit, vegetable and grain consumption led to an attenuation of the point estimate to nonsignificance for the comparison between fried fish consumption of $\geq 2$ servings/week $v$. $<1$ serving/month $(\mathrm{HR}=1.45 ; 95 \% \mathrm{CI} 0.96,2 \cdot 20 ; P$ for linear trend $=0.22)$. Sensitivity analyses examining the inclusion of an additional 4926 participants who were excluded due to history of stroke, transient ischaemic attack or CVD found that the observed association between fried fish consumption of $\geq 2$ servings/week $v .<1$ serving/month was attenuated to non-significance (HR $=1 \cdot 34 ; 95 \%$ CI 0.99, 1.82; $P$ for linear trend $=0.09)$ after the inclusion of these participants.

Additional analyses investigating associations between fried and non-fried fish consumption with individual events including incident MI or ischaemic stroke, cardiovascular and all-cause mortality are included in Appendices 1 to 4 . After adjustment for potential confounders, fried fish consumption of $\geq 2$ servings/week ( $v .<1$ serving/month) was associated with a trend towards increased risk of MI $(\mathrm{HR}=1.48 ; 95 \%$ CI $0.90,2.43 ; P$ for trend $=0.22)$ and ischaemic stroke $(\mathrm{HR}=1.83 ; 95 \%$ CI $0.99,3.39 ; P$ for trend $=0.05)$ in separate analyses; no significant associations were found between fried or non-fried fish consumption with either all-cause or CVD mortality.

\section{Discussion}

In the present large prospective study, we found that participants who consumed fried fish more than twice weekly were at a 1.63 times increased risk of CVD compared with those consuming fried fish less than once monthly. Non-fried fish consumption was not associated with a significant effect on CVD risk in any of the adjusted models and no association was identified between fish consumption and all-cause or cardiovascular mortality.

Prospective cohort studies have in general found inverse associations between fish intake and risk of CVD. However, the type and preparation of the fish meal have also been found to impact the potential benefits on cardiovascular risk in previous studies, one showing that intake of fried fish more than once per week was associated with a $44 \%$ higher risk of ischaemic stroke and the other showing a trend towards higher risk of MI compared with consumption of less than once per month ${ }^{(22,42)}$. In addition to the increased energy intake associated with fried compared with non-fried fish, most fish served fried in the USA tends to be from lean species which are lower in $n-3$ fatty acids ${ }^{(36)}$. The act of frying fish has also been 
Table 1 Descriptive characteristics of participants ( $n 16$ 479) in the REasons for Geographic And Racial Differences in Stroke (REGARDS) study by frequency and type of fish consumption

\begin{tabular}{|c|c|c|c|c|c|}
\hline \multirow[b]{2}{*}{ Characteristic } & \multicolumn{4}{|c|}{ Fried fish consumption } & \multirow[b]{2}{*}{$P$ value } \\
\hline & $\begin{array}{c}<1 \text { serving/month } \\
(n 7849)\end{array}$ & $\begin{array}{c}1-3 \text { servings/month } \\
(n \text { 6464) }\end{array}$ & $\begin{array}{c}1-1.99 \text { servings/week } \\
(\text { ( 1576) }\end{array}$ & $\begin{array}{c}\geq 2 \text { servings/week } \\
\text { ( } \text { ( 590) }\end{array}$ & \\
\hline \multicolumn{5}{|l|}{ Age group (\%) } & \multirow[t]{5}{*}{0.07} \\
\hline $40-54$ years & $13 \cdot 3$ & $14 \cdot 4$ & $11 \cdot 7$ & $14 \cdot 9$ & \\
\hline $55-64$ years & 41.4 & 41.4 & $41 \cdot 7$ & 43.6 & \\
\hline $65-74$ years & $31 \cdot 3$ & $31 \cdot 3$ & $32 \cdot 9$ & $30 \cdot 0$ & \\
\hline$\geq 75$ years & $14 \cdot 0$ & $12 \cdot 9$ & 13.7 & 11.5 & \\
\hline \multicolumn{5}{|l|}{ Race (\%) } & \multirow[t]{3}{*}{$<0.0001$} \\
\hline Black & 21.0 & $40 \cdot 8$ & $59 \cdot 1$ & 73.7 & \\
\hline White & 79.0 & $59 \cdot 2$ & $40 \cdot 9$ & $26 \cdot 3$ & \\
\hline \multicolumn{5}{|l|}{$\operatorname{Sex}(\%)$} & \multirow[t]{3}{*}{$<0.0001$} \\
\hline Male & $37 \cdot 6$ & 43.4 & $44 \cdot 3$ & $41 \cdot 7$ & \\
\hline Female & $62 \cdot 4$ & $56 \cdot 6$ & $55 \cdot 7$ & $58 \cdot 3$ & \\
\hline \multicolumn{5}{|l|}{ Region (\%) } & \multirow[t]{3}{*}{$<0.0001$} \\
\hline Stroke belt or buckle & $53 \cdot 3$ & $59 \cdot 0$ & $60 \cdot 6$ & $58 \cdot 6$ & \\
\hline Non-belt or buckle & $46 \cdot 7$ & 41.0 & 39.4 & 41.4 & \\
\hline \multicolumn{6}{|l|}{ Education (\%) } \\
\hline Less than high school & $6 \cdot 2$ & $9 \cdot 4$ & $12 \cdot 0$ & $15 \cdot 6$ & \multirow[t]{4}{*}{$<0.0001$} \\
\hline High-school graduate & $22 \cdot 6$ & $26 \cdot 3$ & 28.2 & 30.5 & \\
\hline Some college & $26 \cdot 8$ & 28.0 & 29.2 & $28 \cdot 1$ & \\
\hline College + & 44.5 & $36 \cdot 3$ & $30 \cdot 7$ & $25 \cdot 8$ & \\
\hline \multicolumn{6}{|l|}{ Annual income (\%) } \\
\hline$<\$$ US 20000 & $12 \cdot 4$ & 14.8 & $18 \cdot 4$ & 23.1 & \multirow[t]{5}{*}{$<0.0001$} \\
\hline \$US $20000-34999$ & $21 \cdot 3$ & $24 \cdot 0$ & $26 \cdot 8$ & $27 \cdot 6$ & \\
\hline \$US 35 000-74 999 & 32.6 & $32 \cdot 7$ & $31 \cdot 3$ & $26 \cdot 3$ & \\
\hline$\geq \$$ US 75000 & 21.5 & $17 \cdot 3$ & $12 \cdot 6$ & 10.5 & \\
\hline Refused & $12 \cdot 2$ & $11 \cdot 3$ & $10 \cdot 9$ & $12 \cdot 5$ & \\
\hline Exercise (\%) & & & & & 0.17 \\
\hline 0 times/week & $31 \cdot 0$ & 31.5 & $32 \cdot 5$ & 29.2 & \\
\hline 1-3 times/week & 38.0 & 38.8 & $36 \cdot 5$ & $36 \cdot 4$ & \\
\hline$\geq 4$ times/week & 31.0 & 29.7 & $31 \cdot 0$ & 34.5 & \\
\hline Current smoker (\%) & $12 \cdot 0$ & 14.5 & $14 \cdot 1$ & $14 \cdot 1$ & 0.0001 \\
\hline Diabetes (\%) & 13.2 & $17 \cdot 6$ & $21 \cdot 8$ & 23.9 & $<0.0001$ \\
\hline Regular aspirin use (\%) & $38 \cdot 1$ & $36 \cdot 9$ & 34.9 & 35.9 & 0.07 \\
\hline Dyslipidaemia (\%) & 54.0 & $56 \cdot 3$ & 54.9 & $53 \cdot 2$ & 0.04 \\
\hline Hypertensive medication (\%) & $42 \cdot 8$ & 48.6 & 53.4 & $57 \cdot 1$ & $<0.0001$ \\
\hline Total energy intake $(\mathrm{kJ} / \mathrm{d})$, mean & 6623 & 7360 & 8247 & 9858 & $<0.0001$ \\
\hline $\mathrm{SD}$ & 2632 & 3025 & 3234 & 3874 & \\
\hline Total energy intake $(\mathrm{kcal} / \mathrm{d})$, mean & 1583 & 1759 & 1971 & 2356 & $<0.0001$ \\
\hline SD & 629 & 723 & 773 & 926 & \\
\hline BMI $\left(\mathrm{kg} / \mathrm{m}^{2}\right)$, mean & $28 \cdot 3$ & 29.5 & 29.9 & 30.9 & $<0.0001$ \\
\hline SD & $5 \cdot 8$ & $6 \cdot 3$ & $6 \cdot 3$ & $6 \cdot 6$ & \\
\hline Mediterranean diet score, mean & $4 \cdot 3$ & 4.3 & 4.6 & 4.7 & $<0.0001$ \\
\hline SD & $1 \cdot 7$ & 1.7 & 1.6 & 1.4 & \\
\hline Systolic blood pressure $(\mathrm{mmHg})$, mean & $124 \cdot 7$ & $126 \cdot 6$ & 128.5 & 130.5 & $<0.0001$ \\
\hline SD & $15 \cdot 6$ & $16 \cdot 0$ & $16 \cdot 1$ & $17 \cdot 7$ & \\
\hline & & Non-fried fis & h consumption & & \\
\hline & $\begin{array}{c}<1 \text { serving/month } \\
(n 3541)\end{array}$ & $\begin{array}{c}\text { 1-3 servings/month } \\
(n \text { 8687) }\end{array}$ & $\begin{array}{c}\text { 1-1.99 servings/week } \\
\text { (n 2522) }\end{array}$ & $\begin{array}{c}\geq 2 \text { servings/week } \\
(n 1729)\end{array}$ & $P$ value $\dagger$ \\
\hline Age group (\%) & & & & & 0.0002 \\
\hline $40-54$ years & $13 \cdot 5$ & $14 \cdot 0$ & $12 \cdot 6$ & 13.7 & \\
\hline $55-64$ years & 38.4 & $42 \cdot 1$ & 43.1 & $42 \cdot 3$ & \\
\hline $65-74$ years & $32 \cdot 7$ & $30 \cdot 8$ & $30 \cdot 9$ & $32 \cdot 4$ & \\
\hline$\geq 75$ years & $15 \cdot 3$ & 13.0 & $13 \cdot 4$ & $11 \cdot 7$ & \\
\hline Race $(\%)$ & & & & & \\
\hline Black & $38 \cdot 2$ & 33.5 & $28 \cdot 7$ & $38 \cdot 3$ & $<0.0001$ \\
\hline White & $61 \cdot 8$ & 66.5 & 71.3 & $61 \cdot 7$ & \\
\hline $\operatorname{Sex}(\%)$ & & & & & 0.001 \\
\hline Male & $41 \cdot 0$ & $41 \cdot 4$ & $40 \cdot 8$ & $36 \cdot 3$ & \\
\hline Female & $59 \cdot 0$ & $58 \cdot 6$ & 59.2 & 63.7 & \\
\hline Region (\%) & & & & & $<0.0001$ \\
\hline Stroke belt or buckle & $60 \cdot 3$ & $57 \cdot 1$ & 52.4 & $51 \cdot 0$ & \\
\hline Non-belt or buckle & 39.7 & $42 \cdot 9$ & $47 \cdot 6$ & $49 \cdot 0$ & \\
\hline
\end{tabular}




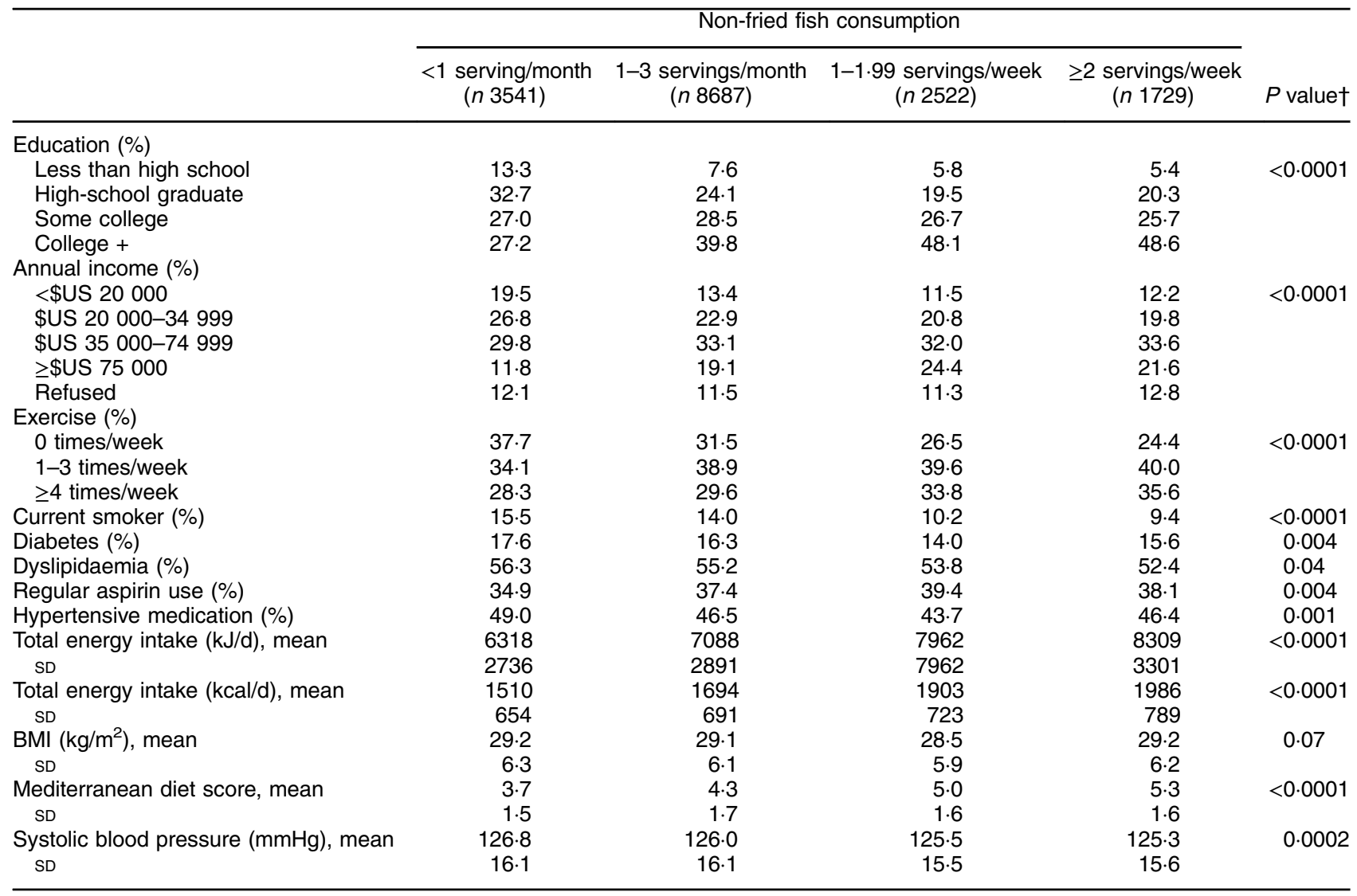

$T x^{2} P$ values for test of proportions; ANOVA $P$ values for test on mean differences.

Table 2 Hazard ratios (HR) and $95 \% \mathrm{Cl}$ of fish consumption and risk of CVD among participants ( $n 16479)$ in the REasons for Geographic And Racial Differences in Stroke (REGARDS) study, USA

\begin{tabular}{|c|c|c|c|c|c|c|c|c|c|c|}
\hline & \multirow[b]{2}{*}{ Person-years } & \multirow[b]{2}{*}{ Events } & \multicolumn{2}{|c|}{ Crude } & \multicolumn{2}{|c|}{ Model 1} & \multicolumn{2}{|c|}{ Model 2} & \multicolumn{2}{|c|}{ Model 3} \\
\hline & & & HR & $95 \% \mathrm{Cl}$ & $\mathrm{HR}$ & $95 \% \mathrm{Cl}$ & $\mathrm{HR}$ & $95 \% \mathrm{Cl}$ & $\mathrm{HR}$ & $95 \% \mathrm{Cl}$ \\
\hline \multicolumn{11}{|l|}{ Fried fish consumption } \\
\hline$<1$ serving/month (ref.) & 39947 & 280 & \multicolumn{2}{|c|}{1} & \multicolumn{2}{|c|}{1} & \multicolumn{2}{|c|}{1} & \multicolumn{2}{|c|}{1} \\
\hline 1-3 servings/month & 32608 & 310 & 1.36 & $1.15,1.59$ & 1.25 & $1.06,1.47$ & 1.24 & $1.04,1.47$ & 1.20 & $1.01,1.43$ \\
\hline 1-1.99 servings/week & 7971 & 76 & 1.36 & $1.05,1.75$ & $1 \cdot 13$ & $0.87,1.47$ & $1 \cdot 17$ & $0.89,1.54$ & 1.09 & $0.82,1.45$ \\
\hline$\geq 2$ servings/week & 2905 & 34 & 1.67 & $1.17,2.39$ & 1.47 & $1 \cdot 02,2 \cdot 12$ & 1.63 & $1 \cdot 12,2 \cdot 38$ & 1.63 & $1.11,2.40$ \\
\hline$P$ for trend & & & \multicolumn{2}{|c|}{$<0.0001$} & \multicolumn{2}{|c|}{0.02} & \multicolumn{2}{|c|}{0.008} & \multicolumn{2}{|c|}{0.03} \\
\hline \multicolumn{11}{|l|}{ Non-fried fish consumption } \\
\hline$<1$ serving/month (ref.) & 17669 & 160 & \multicolumn{2}{|c|}{1} & \multicolumn{2}{|c|}{1} & \multicolumn{2}{|c|}{1} & \multicolumn{2}{|c|}{1} \\
\hline $1-3$ servings/month & 44133 & 387 & 0.97 & $0.80,1.16$ & $1 \cdot 11$ & $0.92,1.34$ & $1 \cdot 14$ & $0.94,1.38$ & $1 \cdot 11$ & $0.91,1.36$ \\
\hline $1-1.99$ servings/week & 12853 & 95 & 0.82 & $0.63,1.05$ & 0.98 & $0.76,1.27$ & 1.04 & $0.79,1.37$ & 1.09 & $0.82,1.44$ \\
\hline$\geq 2$ servings/week & 8776 & 58 & 0.73 & $0.54,0.98$ & 0.93 & $0.68,1.26$ & 1.01 & $0.73,1.40$ & 1.09 & $0.78,1.52$ \\
\hline$P$ for trend & & & \multicolumn{2}{|c|}{0.02} & \multicolumn{2}{|c|}{0.54} & \multicolumn{2}{|c|}{0.95} & \multicolumn{2}{|c|}{0.57} \\
\hline
\end{tabular}

Ref., reference category.

Model 1 adjusts for age, race, region, sex, income and education. Model 2 additionally adjusts for exercise, smoking status, Mediterranean diet score, regular aspirin use and total energy intake ( $\mathrm{kcal} / \mathrm{d})$. Model 3 additionally adjusts for current use of hypertensive medication, diabetes status, systolic blood pressure, $\mathrm{BMI}$ and dyslipidaemia.

associated with loss of the natural $n-3$ fatty acids in the fish and replacement with cooking oil ${ }^{(43)}$. While the consumption of fried fish may directly contribute to increased cardiovascular risk through these mechanisms, fried fish intake may also represent a marker of less healthy dietary patterns which may contribute to $\mathrm{CVD}^{(22,42)}$. We included participants' adherence to a Mediterranean diet in our model to assess whether dietary patterns affected our findings; however, there was no attenuation in the HR.

We have previously reported in the REGARDS cohort that African Americans were significantly more likely than whites to have $\geq 2$ servings fried fish/week (OR $=3 \cdot 59 ; 95 \%$ CI $3 \cdot 19,4 \cdot 04)^{(37)}$. Additionally, we found that participants living in the stroke belt were significantly more likely than 
those living outside the stroke belt to have $\geq 2$ servings fried fish/week (OR=1.32; 95\% CI 1.17, 1.50). Based on our current results associating fried fish intake with an increased risk of incident MI and ischaemic stroke, these data suggest that racial and regional differences in dietary fried fish intake could contribute to disparities in CVD.

Our study was strengthened by the prospective design. While our HR estimates remained largely unchanged after controlling for potential confounders, the possibility of residual confounding by unknown risk factors cannot be excluded. We utilized a previously validated FFQ; however, dietary assessment was performed at baseline only and therefore we cannot account for potential dietary changes over time. Additionally, our FFQ data provided no information on the main types of fats used for frying and the main types of fish consumed, limiting our ability to assess their effects on events. In analyses of incident MI or ischaemic stroke alone, we found a trend towards increased risk with fried fish consumption although this did not reach significance; there was also no significant association with cardiovascular mortality, which is likely due to the reduced power as a result of low numbers of events when assessing the individual outcomes separately or when assessing cardiovascular mortality.

\section{Conclusion}

In conclusion, we observed that fried fish intake of $\geq 2$ servings/week is associated with an increased risk of cardiovascular events. Given the increased intake of fried fish in the stroke belt and among African Americans, these data suggest that dietary fried fish intake may contribute to geographic and racial disparities in CVD.

\section{Acknowledgements}

Acknowledgements: The authors thank the other investigators, staff and participants of the REGARDS study for their valuable contributions. A full list of participating REGARDS investigators and institutions can be found at http://www.regardsstudy.org. Portions of these data were presented at the International Stroke Conference, New Orleans, Louisiana, USA, on 2 February 2012. Financial support: This research project is supported by the National Institute of Neurological Disorders and Stroke, National Institutes of Health, Department of Health and Human Services (cooperative agreement U01 NS041588). Additional support was provided by the National Heart, Lung, and Blood Institute (grant number R01 HL08477). Funding for coding of the Block FFQ was provided by General Mills. The content is solely the responsibility of the authors and does not necessarily represent the official views and positions of the National Institute of Neurological Disorders and Stroke or the
National Institutes of Health. Representatives of the funding agency were involved in the review of the manuscript prior to submission for publication. Conflict of interest: There are no conflicts of interest to disclose. Autborship: F.N.: study concept and design, analysis and interpretation, critical revision of manuscript for important intellectual content, study supervision. K.P.: study concept and design, analysis and interpretation, critical revision of manuscript for important intellectual content. M.R.F.: acquisition of data, analysis and interpretation, critical revision of manuscript for important intellectual content. J.A.: acquisition of data, analysis and interpretation, critical revision of manuscript for important intellectual content. M.M.S.: acquisition of data, analysis and interpretation, critical revision of manuscript for important intellectual content, study supervision. D.K.: acquisition of data, analysis and interpretation, critical revision of manuscript for important intellectual content, study supervision. V.J.H.: study concept and design, acquisition of data, analysis and interpretation, critical revision of manuscript for important intellectual content, study supervision. S.J.: study concept and design, acquisition of data, analysis and interpretation, critical revision of manuscript for important intellectual content, study supervision. Ethics of human subject participation: This study was conducted according to the guidelines laid down in the Declaration of Helsinki and all procedures involving human subjects/patients were approved by the University of Alabama, Birmingham institutional review board. The study methods were reviewed and approved by the institutional review boards of participating institutions. Informed consent was obtained initially on the telephone and subsequently in writing during the in-person evaluation.

\section{References}

1. Borhani NO (1965) Changes and geographic distribution of mortality from cerebrovascular disease. Am J Public Health 55, 673-681.

2. Lanska DJ \& Kuller LH (1995) The geography of stroke mortality in the United States and the concept of a stroke belt. Stroke 26, 1145-1149.

3. Casper ML, Barnett E, Williams GI Jr et al. (2003) Atlas of Stroke Mortality: Racial, Ethnic, and Geographic Disparities in the United States. Atlanta, GA: Department of Health and Human Services, Centers for Disease Control and Prevention.

4. Howard VJ, Cushman M, Pulley L et al. (2005) The reasons for geographic and racial differences in stroke study: objectives and design. Neuroepidemiology 25, 135-143.

5. Howard VJ, Kleindorfer DO, Judd SE et al. (2011) Disparities in stroke incidence contributing to disparities in stroke mortality. Ann Neurol 69, 619-627.

6. Howard G, Anderson R, Sorlie P et al. (1994) Ethnic differences in stroke mortality between non-Hispanic whites, Hispanic whites, and blacks. The National Longitudinal Mortality Study. Stroke 25, 2120-2125.

7. Gillum RF (1999) Stroke mortality in blacks. Disturbing trends. Stroke 30, 1711-1715. 
8. Howard G \& Howard VJ (2001) Ethnic disparities in stroke: the scope of the problem. Ethn Dis 11, 761-768.

9. Anand RG, Alkadri M, Lavie CJ et al. (2008) The role of fish oil in arrhythmia prevention. J Cardiopulm Rehabil Prev $\mathbf{2 8}$, 2-8.

10. O'Keefe JH Jr, Abuissa H, Sastre A et al. (2006) Effects of omega-3 fatty acids on resting heart rate, heart rate recovery after exercise, and heart rate variability in men with healed myocardial infarctions and depressed ejection fraction. $\mathrm{Am} \mathrm{J}$ Cardiol 97, 1127-1130.

11. Ventura HO, Milani RV, Lavie CJ et al. (1993) Cyclosporineinduced hypertension: efficacy of omega-3 fatty acids in patients after cardiac transplantation. Circulation 88, 281-285.

12. Thies F, Garry JM, Yaqoob P et al. (2003) Association of $n-3$ polyunsaturated fatty acids with stability of atherosclerotic plaques: a randomized controlled trial. Lancet 361, 477-485.

13. Din JN, Harding SA, Valerio CJ et al. (2008) Dietary intervention with oil rich fish reduces platelet-monocyte aggregation in man. Atherosclerosis 197, 290-296.

14. Geleijnse JM, Giltay EJ, Grobbee DE et al. (2002) Blood pressure response to fish oil supplementation: metaregression analysis of randomized trials. $J$ Hypertens 20, 1493-1499.

15. Zhao G, Etherton TD, Martin KR et al. (2007) Dietary $\alpha$-linolenic acid inhibits proinflammatory cytokine productions by peripheral blood mononuclear cells in hypercholesterolemic subjects. Am J Clin Nutr 85, 385-391.

16. Mehra MR, Lavie CJ, Ventura HO et al. (2006) Fish oils produce anti-inflammatory effects and improve body weight in severe heart failure. J Heart Lung Transplant 25, 834-838.

17. Davidson MH, Stein EA, Bayes HE et al.; COMBination of prescription Omega-3 with Simvastatin (COMBOS) Investigators (2007) Efficacy and tolerability of adding prescription omega- 3 fatty acids $4 \mathrm{~g} / \mathrm{d}$ to simvastatin $40 \mathrm{mg} / \mathrm{d}$ in hypertriglyceridemic patients: an 8-week, randomized, double-blind, placebo-controlled study. Clin Ther 29, $1354-1367$.

18. Caicoya M (2002) Fish consumption and stroke: a community case control study in Asturias, Spain. Neuroepidemiology 21, 107-114.

19. Hunter DJ, Kazda I, Chockalingam A et al. (1988) Fish consumption and cardiovascular mortality in Canada: an inter-regional comparison. Am J Prev Med 4, 5-10.

20. Zhang J, Sasaki S, Amano K et al. (1999) Fish consumption and mortality from all causes, ischemic heart disease, and stroke: an ecological study. Prev Med 28, 520-529.

21. Ding EL \& Mozaffarian D (2006) Optimal dietary habits for the prevention of stroke. Semin Neurol 26, 11-23.

22. Mozaffarian D, Longstreth WT Jr, Lemaitre RN et al. (2005) Fish consumption and stroke risk in elderly individuals: the cardiovascular health study. Arch Intern Med 165, 200-206.

23. He K, Song Y, Daviglus ML et al. (2004) Fish consumption and incidence of stroke: a meta-analysis of cohort studies. Stroke 35, 1538-1542.

24. Chowdhury R, Stevens S, Gorman D et al. (2012) Association between fish consumption, long chain omega 3 fatty acids, and risk of cerebrovascular disease: systematic review and meta-analysis. BMJ 345, e6698.

25. Larsson S, Orsini N \& Wolk A (2012) Long-chain omega-3 polyunsaturated fatty acids and risk of stroke: a metaanalysis. Eur J Epidemiol 27, 895-901.

26. Mozaffarian D, Lemaitre RN, King IB et al. (2013) Plasma phospholipid long-chain $\omega$ - 3 fatty acids and total and causespecific mortality in older adults: a cohort study. Ann Intern Med 158, 515-525.

27. Gruppo Italiano per lo Studio della Sopravvivenza nell'Infarto miocardico (1999) Dietary supplementation with $n-3$ polyunsaturated fatty acids and vitamin E after myocardial infarction: results of the GISSI-Prevenzione trial. Lancet 354, 447-455.

28. Yokoyama M, Origasa $\mathrm{H}$, Matsuzaki $\mathrm{M}$ et al.; Japan EPA Lipid Intervention Study (JELIS) Investigators (2007) Effects of eicosapentaenoic acid on major coronary events in hypercholesterolaemic patients (JELIS): a randomised open-label, blinded endpoint analysis. Lancet 369 , 1090-1098.

29. Marchioli R, Barzi F, Bomba E et al.; GISSI-Prevenzione Investigators (2002) Early protection against sudden death by $n-3$ polyunsaturated fatty acids after myocardial infarction: time-course analysis of the results of the Gruppo Italiano per lo Studio della Sopravvivenza nell'Infarto miocardico (GISSI)-Prevenzione. Circulation 105, 1897-1903.

30. Tavazzi L, Maggioni AP, Marchioli $\mathrm{R}$ et al.; GISSI-HF Investigators (2008) Effect of $n-3$ polyunsaturated fatty acids in patients with chronic heart failure (the GISSI-HF trial): a randomised, double-blind, placebo-controlled trial. Lancet 372, 1223-1230.

31. Casula M, Soranna D, Catapano AL et al. (2013) Long-term effect of high dose omega-3 fatty acid supplementation for secondary prevention of cardiovascular outcomes: a meta-analysis of randomized, double blind, placebo controlled trials. Atheroscler Suppl 14, 243-251.

32. Kromhout D, Giltay EJ \& Geleijnse JM (2010) N-3 fatty acids and cardiovascular events after myocardial infarction. N Engl J Med 363, 2015-2026.

33. Galan P, Kesse-Guyot E, Czernichow S et al. (2010) Effects of $\mathrm{B}$ vitamins and omega 3 fatty acids on cardiovascular diseases: a randomised placebo controlled trial. BMJ $\mathbf{3 4 1}$, c6273.

34. The ORIGIN Trial Investigators (2012) N-3 fatty acids and cardiovascular outcomes in patients with dysglycemia. N Engl J Med 367, 309-318.

35. Roncaglioni MC, Tombesi M, Avanzini F et al. (2013) N-3 fatty acids in patients with multiple cardiovascular risk factors. N Engl J Med 368, 1800-1808.

36. Kris-Etherton PM, Harris WS \& Appel LJ, American Heart Association, Nutrition Committee (2002) Fish consumption, fish oil, omega-3 fatty acids, and cardiovascular disease. Circulation 106, 2747-2757.

37. Nahab F, Le A, Judd S et al. (2011) Racial and geographic differences in fish consumption: the REGARDS study. Neurology 76, 154-158.

38. Anon. (1989) Stroke - 1989. Recommendations on stroke prevention, diagnosis and therapy. Report of the WHO Task Force on Stroke and other Cerebrovascular Disorders. Stroke 20, 1407-1431.

39. Safford MM, Brown TM, Muntner PM et al. REGARDS Investigators (2012) Association of race and sex with risk of incident acute coronary heart disease events. JAMA 308, $1768-1774$.

40. Diaz KM, Booth JN III, Calhoun DA et al. (2014) Healthy lifestyle factors and risk of cardiovascular events and mortality in treatment-resistant hypertension: the Reasons for Geographic and Racial Differences in Stroke Study. Hypertension 64, 465-471.

41. Tsivgoulis G, Judd S, Letter AJ et al. (2013) Adherence to a Mediterranean diet and risk of incident cognitive impairment. Neurology 80, 1684-1692.

42. Mozaffarian D, Lemaitre RN, Kuller LH et al. (2003) Cardiac benefits of fish consumption may depend on the type of fish meal consumed: the Cardiovascular Health Study. Circulation 107, 1372-1377.

43. Candela M, Astiasaran I \& Bello J (1998) Deep-fat frying modifies high-fat fish lipid fraction. J Agric Food Chem 46, 2793-2796. 


\section{Appendix 1}

Hazard ratios (HR) and $95 \%$ CI of fish consumption and risk of myocardial infarction among participants (n 16479$)$ in the REasons for Geographic And Racial Differences in Stroke (REGARDS) study, USA

\begin{tabular}{|c|c|c|c|c|c|c|c|c|c|c|}
\hline & \multirow[b]{2}{*}{ Person-years } & \multirow[b]{2}{*}{ Events } & \multicolumn{2}{|c|}{ Crude } & \multicolumn{2}{|c|}{ Model 1} & \multicolumn{2}{|c|}{ Model 2} & \multicolumn{2}{|c|}{ Model 3} \\
\hline & & & $\mathrm{HR}$ & $95 \% \mathrm{Cl}$ & $\mathrm{HR}$ & $95 \% \mathrm{Cl}$ & HR & $95 \% \mathrm{Cl}$ & $\mathrm{HR}$ & $95 \% \mathrm{Cl}$ \\
\hline \multicolumn{11}{|l|}{ Fried fish consumption } \\
\hline$<1$ serving/month (ref.) & 39947 & 178 & \multicolumn{2}{|c|}{1} & \multicolumn{2}{|c|}{1} & \multicolumn{2}{|c|}{1} & \multicolumn{2}{|c|}{1} \\
\hline $1-3$ servings/month & 32608 & 195 & 1.34 & $1.10,1.64$ & 1.22 & $0.99,1.50$ & $1 \cdot 20$ & $0.97,1.48$ & 1.15 & $0.92,1.43$ \\
\hline 1-2 servings/week & 7971 & 46 & 1.29 & $0.93,1.79$ & 1.08 & $0.78,1.51$ & $1 \cdot 12$ & $0.79,1.57$ & 1.02 & $0.71,1.47$ \\
\hline$\geq 2$ servings/week & 2905 & 21 & 163 & $1.03,2.55$ & 1.43 & $0.90,2.29$ & 1.49 & $0.92,2.41$ & 1.48 & $0.90,2.43$ \\
\hline$P$ for trend & & & \multicolumn{2}{|c|}{0.004} & \multicolumn{2}{|c|}{0.11} & \multicolumn{2}{|c|}{0.10} & \multicolumn{2}{|c|}{0.22} \\
\hline \multicolumn{11}{|l|}{ Non-fried fish consumption } \\
\hline$<1$ serving/month (ref.) & 17669 & 103 & \multicolumn{2}{|c|}{1} & \multicolumn{2}{|c|}{1} & \multicolumn{2}{|c|}{1} & \multicolumn{2}{|c|}{1} \\
\hline $1-3$ servings/month & 44133 & 248 & 0.96 & $0.76,1.21$ & $1 \cdot 11$ & $0.88,1.40$ & 1.09 & $0.86,1.38$ & 1.05 & $0.82,1.35$ \\
\hline 1-2 servings/week & 12853 & 56 & 0.75 & $0.54,1.03$ & 0.91 & $0.65,1.26$ & 0.89 & $0.63,1.25$ & 0.93 & $0.65,1.32$ \\
\hline$\geq 2$ servings/week & 8776 & 33 & 0.64 & $0.44,0.95$ & 0.82 & $0.55,1.23$ & 0.83 & $0.55,1.27$ & 0.87 & $0.56,1.35$ \\
\hline$P$ for trend & & & \multicolumn{2}{|c|}{0.008} & \multicolumn{2}{|c|}{0.26} & \multicolumn{2}{|c|}{0.30} & \multicolumn{2}{|c|}{0.47} \\
\hline
\end{tabular}

Ref., reference category.

Model 1 adjusts for age, race, region, sex, income and education. Model 2 additionally adjusts for exercise, smoking status, Mediterranean diet score, regular aspirin use and total energy intake (kcal/d). Model 3 additionally adjusts for current use of hypertensive medication, diabetes status, systolic blood pressure, $\mathrm{BMI}$ and dyslipidaemia.

\section{Appendix 2}

Hazard ratios (HR) and $95 \%$ CI of fish consumption and risk of ischaemic stroke among participants (n 16479$)$ in the REasons for Geographic And Racial Differences in Stroke (REGARDS) study, USA

\begin{tabular}{|c|c|c|c|c|c|c|c|c|c|c|}
\hline & \multirow[b]{2}{*}{ Person-years } & \multirow[b]{2}{*}{ Events } & \multicolumn{2}{|c|}{ Crude } & \multicolumn{2}{|c|}{ Model 1} & \multicolumn{2}{|c|}{ Model 2} & \multicolumn{2}{|c|}{ Model 3} \\
\hline & & & $\mathrm{HR}$ & $95 \% \mathrm{Cl}$ & $\mathrm{HR}$ & $95 \% \mathrm{Cl}$ & $\mathrm{HR}$ & $95 \% \mathrm{Cl}$ & $\mathrm{HR}$ & $95 \% \mathrm{Cl}$ \\
\hline \multicolumn{11}{|l|}{ Fried fish consumption } \\
\hline$<1$ serving/month (ref.) & 39947 & 105 & \multicolumn{2}{|c|}{1} & \multicolumn{2}{|c|}{1} & \multicolumn{2}{|c|}{1} & \multicolumn{2}{|c|}{1} \\
\hline $1-3$ servings/month & 32608 & 116 & 1.35 & $1.04,1.76$ & 1.25 & $0.96,1.64$ & 1.27 & $0.96,1.68$ & 1.28 & $0.96,1.70$ \\
\hline 1-2 servings/week & 7971 & 31 & 1.48 & $0.99,2 \cdot 21$ & $1 \cdot 20$ & $0.79,1.82$ & 1.27 & $0.82,1.96$ & 1.23 & $0.78,1.93$ \\
\hline$\geq 2$ servings/week & 2905 & 13 & 1.71 & $0.96,3.04$ & 1.47 & $0.82,2.67$ & 1.82 & $0.99,3.35$ & 1.83 & $0.99,3.39$ \\
\hline$P$ for trend & & & \multicolumn{2}{|c|}{0.006} & \multicolumn{2}{|c|}{0.11} & \multicolumn{2}{|c|}{0.04} & \multicolumn{2}{|c|}{0.05} \\
\hline \multicolumn{11}{|l|}{ Non-fried fish consumption } \\
\hline$<1$ serving/month (ref.) & 17669 & 57 & \multicolumn{2}{|c|}{1} & \multicolumn{2}{|c|}{1} & \multicolumn{2}{|c|}{1} & \multicolumn{2}{|c|}{1} \\
\hline $1-3$ servings/month & 44133 & 143 & 1.00 & $0.74,1.36$ & $1 \cdot 16$ & $0.85,1.58$ & 1.27 & $0.92,1.74$ & $1 \cdot 24$ & $0.89,1.74$ \\
\hline 1-2 servings/week & 12853 & 39 & 0.94 & $0.63,1.41$ & 1.13 & $0.75,1.71$ & 1.36 & $0 \cdot 88,2 \cdot 10$ & 1.41 & $0.90,2.21$ \\
\hline$\geq 2$ servings/week & 8776 & 26 & 0.92 & $0.58,1.46$ & 1.15 & $0.72,1.84$ & 1.43 & $0.87,2.36$ & 1.58 & $0.95,2.63$ \\
\hline$P$ for trend & & & \multicolumn{2}{|c|}{0.65} & \multicolumn{2}{|c|}{0.55} & \multicolumn{2}{|c|}{0.12} & \multicolumn{2}{|c|}{0.06} \\
\hline
\end{tabular}

Ref., reference category.

Model 1 adjusts for age, race, region, sex, income and education. Model 2 additionally adjusts for exercise, smoking status, Mediterranean diet score, regular aspirin use and total energy intake ( $\mathrm{kcal} / \mathrm{d})$. Model 3 additionally adjusts for current use of hypertensive medication, diabetes status, systolic blood pressure, $\mathrm{BMI}$ and dyslipidaemia. 
Appendix 3

Hazard ratios (HR) and $95 \%$ CI of fish consumption and risk of CVD mortality among participants (n 16479) in the REasons for Geographic And Racial Differences in Stroke (REGARDS) study, USA

\begin{tabular}{|c|c|c|c|c|c|c|c|c|c|c|}
\hline & \multirow[b]{2}{*}{ Person-years } & \multirow[b]{2}{*}{ Events } & \multicolumn{2}{|r|}{ Crude } & \multicolumn{2}{|c|}{ Model 1} & \multicolumn{2}{|c|}{ Model 2} & \multicolumn{2}{|c|}{ Model 3} \\
\hline & & & HR & $95 \% \mathrm{Cl}$ & HR & $95 \% \mathrm{Cl}$ & $\mathrm{HR}$ & $95 \% \mathrm{Cl}$ & $\mathrm{HR}$ & $95 \% \mathrm{Cl}$ \\
\hline \multicolumn{11}{|l|}{ Fried fish consumption } \\
\hline$<1$ serving/month (ref.) & 40572 & 122 & \multicolumn{2}{|r|}{1} & \multicolumn{2}{|c|}{1} & \multicolumn{2}{|c|}{1} & \multicolumn{2}{|c|}{1} \\
\hline 1-3 servings/month & 33289 & 129 & 1.28 & $1.00,1.64$ & $1 \cdot 12$ & $0.87,1.44$ & $1 \cdot 12$ & $0.86,1.45$ & $1 \cdot 12$ & $0.84,1.47$ \\
\hline 1-1.99 servings/week & 8145 & 30 & 1.21 & $0.81,1.81$ & 0.88 & $0.58,1.32$ & 0.88 & $0.57,1.35$ & 0.78 & $0.48,1.25$ \\
\hline$\geq 2$ servings/week & 3007 & 10 & $1 \cdot 10$ & $0.58,2.09$ & 0.81 & $0.42,1.56$ & 0.81 & $0.40,1.63$ & 0.74 & $0.35,1.55$ \\
\hline $\bar{P}$ for trend & & & \multicolumn{2}{|c|}{0.09} & \multicolumn{2}{|c|}{0.89} & \multicolumn{2}{|c|}{0.39} & \multicolumn{2}{|c|}{0.10} \\
\hline \multicolumn{11}{|l|}{ Non-fried fish consumption } \\
\hline$<1$ serving/month (ref.) & 18042 & 70 & \multicolumn{2}{|c|}{1} & \multicolumn{2}{|c|}{1} & \multicolumn{2}{|c|}{1} & \multicolumn{2}{|c|}{1} \\
\hline $1-3$ servings/month & 44981 & 156 & 0.88 & $0.67,1.17$ & $1 \cdot 11$ & $0.84,1.48$ & $1 \cdot 17$ & $0.86,1.57$ & 1.27 & $0.91,1.76$ \\
\hline 1-1.99 servings/week & 13075 & 41 & 0.80 & $0.55,1.18$ & 1.09 & $0.74,1.62$ & 1.22 & $0.80,1.85$ & 1.39 & $0 \cdot 89,2 \cdot 17$ \\
\hline$\geq 2$ servings/week & 8915 & 24 & 0.69 & $0.43,1.09$ & 1.00 & $0.62,1.59$ & $1 \cdot 18$ & $0.71,1.95$ & 1.46 & $0.87,2.45$ \\
\hline$P$ for trend & & & \multicolumn{2}{|c|}{0.09} & \multicolumn{2}{|c|}{0.89} & \multicolumn{2}{|c|}{0.39} & \multicolumn{2}{|c|}{0.10} \\
\hline
\end{tabular}

Ref., reference category.

Model 1 adjusts for age, race, region, sex, income and education. Model 2 additionally adjusts for exercise, smoking status, Mediterranean diet score, regular aspirin use and total energy intake $(\mathrm{kcal} / \mathrm{d})$. Model 3 additionally adjusts for current use of hypertensive medication, diabetes status, systolic blood pressure, $\mathrm{BMI}$ and dyslipidaemia.

\section{Appendix 4}

Hazard ratios (HR) and $95 \%$ CI of fish consumption and risk of all-cause mortality among participants (n 16479) in the REasons for Geographic And Racial Differences in Stroke (REGARDS) study, USA

\begin{tabular}{|c|c|c|c|c|c|c|c|c|c|c|}
\hline & \multirow[b]{2}{*}{ Person-years } & \multirow[b]{2}{*}{ Events } & \multicolumn{2}{|c|}{ Crude } & \multicolumn{2}{|c|}{ Model 1} & \multicolumn{2}{|c|}{ Model 2} & \multicolumn{2}{|c|}{ Model 3} \\
\hline & & & HR & $95 \% \mathrm{Cl}$ & $\mathrm{HR}$ & $95 \% \mathrm{Cl}$ & $\mathrm{HR}$ & $95 \% \mathrm{Cl}$ & HR & $95 \% \mathrm{Cl}$ \\
\hline \multicolumn{11}{|l|}{ Fried fish consumption } \\
\hline$<1$ serving/month (ref.) & 40572 & 493 & \multicolumn{2}{|c|}{1} & \multicolumn{2}{|c|}{1} & \multicolumn{2}{|c|}{1} & \multicolumn{2}{|c|}{1} \\
\hline 1-3 servings/month & 33289 & 445 & 1.09 & $0.96,1.24$ & 0.98 & $0.86,1.12$ & 0.99 & $0.86,1 \cdot 13$ & 1.00 & $0.87,1.15$ \\
\hline 1-1.99 servings/week & 8145 & 118 & $1 \cdot 18$ & $0.97,1.45$ & 0.90 & $0.73,1.11$ & 0.93 & $0 \cdot 75,1 \cdot 16$ & 0.89 & $0.71,1.13$ \\
\hline$\geq 2$ servings/week & 3007 & 45 & 1.23 & $0.90,1.66$ & 0.95 & $0.69,1.30$ & 1.07 & $0.77,1.48$ & 1.07 & $0.75,1.51$ \\
\hline$P$ for-trend & & & \multicolumn{2}{|c|}{0.04} & \multicolumn{2}{|c|}{0.39} & \multicolumn{2}{|c|}{0.85} & \multicolumn{2}{|c|}{0.75} \\
\hline \multicolumn{11}{|l|}{ Non-fried fish consumption } \\
\hline$<1$ serving/month (ref.) & 18042 & 272 & \multicolumn{2}{|c|}{1} & \multicolumn{2}{|c|}{1} & \multicolumn{2}{|c|}{1} & \multicolumn{2}{|c|}{1} \\
\hline 1-3 servings/month & 44981 & 598 & 0.87 & $0.76,1.01$ & 1.06 & $0.92,1.23$ & $1 \cdot 12$ & $0.96,1.30$ & $1 \cdot 15$ & $0.98,1.35$ \\
\hline $1-1.99$ servings/week & 13075 & 145 & 0.73 & $0.60,0.89$ & 0.95 & $0.77,1.16$ & 1.09 & $0.88,1.35$ & 1.15 & $0.91,1.45$ \\
\hline$\geq 2$ servings/week & 8915 & 86 & 0.63 & $0.50,0.81$ & 0.86 & $0.67,1.10$ & 1.03 & $0.79,1.34$ & 1.18 & $0.90,1.55$ \\
\hline$P$ for trend & & & \multicolumn{2}{|c|}{$<0.0001$} & \multicolumn{2}{|c|}{0.19} & \multicolumn{2}{|c|}{0.63} & \multicolumn{2}{|c|}{0.17} \\
\hline
\end{tabular}

Ref., reference category.

Model 1 adjusts for age, race, region, sex, income and education. Model 2 additionally adjusts for exercise, smoking status, Mediterranean diet score, regular aspirin use and total energy intake $(\mathrm{kcal} / \mathrm{d})$. Model 3 additionally adjusts for current use of hypertensive medication, diabetes status, systolic blood pressure, $\mathrm{BMI}$ and dyslipidaemia. 